\title{
O PRINCÍPIO DA NÃO-CUMULATIVIDADE DO ICMS
}

\author{
IVES GANDRA DA SILVA MARTINS*
}

Carlos da Rocha Guimarães, um dos arquitetos do Código Tributário Nacional, teve, na Comissão do IBDF que examinou o anteprojeto de Rubens Gomes de Souza, papel preponderante, desenvolvendo percuciente análise de muitos dos dispositivos que hoje conformam o Sistema Brasileiro, sempre embasada em seus profundos conhecimentos de filosofia do direito.

Ponto nevrálgico, que em sua teoria merece reflexão, diz respeito ao princípio da não-cumulatividade, cuja origem vem do distante 1958 , quando foi introduzido no então imposto de consumo. Com o advento da E. C. $\mathrm{n}^{2} 18 / 65$, do CTN e das Constituições de 1967 e 1988, ficou definitivamente consagrado, tanto para o IPI quanto para o ICM, hoje ICMS. ${ }^{1}$

É interessante notar que a origem do princípio é, de rigor, o direito francês, tendo eu escrito:

"Embora semelhante, em variados aspectos, ao imposto sobre o valor agregado

l Hamilton Dias de Souza escreve: "O ICM, ao contrário do que tem sido sustentado, não é tributo sobre o valor acrescido, mas sobre operações relativas à circulação de mercadorias.

Na verdade, nos tributos não-cumulativos, o montante devido resulta, ou do valor agregado em cada operaçāo, ou da diferença entre o imposto devido na operação posterior e o exigido na anterior. No primeiro caso, subtrai-se do valor da operação posterior o da anterior, ou ainda, diminui-se do total das vendas o total das compras (dedução na base). No segundo, subtrai-se do imposto devido na operação posterior, o que foi exigível na anterior (dedução do imposto). Aparentemente os dois sistemas produzem resultados idênticos. Tal, porém, não ocorre necessariamente, pois eventuais diferenças de alíquotas ou isenções nas fases precedentes alteram a carga tributária final conforme se adote um ou outro sistema.

No Brasil, adotou-se o sistema de dedução de imposto, nāo de dedução na base. Como salientamos em trabalho anterior, o ICM nāo é imposto sobre o valor agregado, mas sim tributo multifásico não-cumulativo por deduçāo do imposto exigível nas operaçōes precedentes, o que nāo significa que incida ela necessariamente sobre o acréscimo de valor em cada operação. Essa afirmação tanto fica mais clara sabendo-se que a isenção em uma fase anterior do ciclo tem seus efeitos anulados pela incidência total (sem dedução do tributo, que seria devido) na fase ulterior. É o chamado efeito de recuperação" ( $O$ fato gerador do ICM em Caderno de Pesquisas Tributárias no 3, 2플. Tiragem, Co-edição CEEU/Ed. Resenha Tributária, 1991 p. 248/249).

* Professor Emérito da Universidade Mackenzie, Presidente da Academia Internacional de Direito e Economia e do Conselho de Estudos Jurídicos da Federação do Comércio do Estado de São Paulo. 
adotado, com pequenas distinções, por países da Europa e da América, o imposto sobre operações relativas à circulação de mercadorias, no Brasil, tem características diferenciais mais nítidas que as convergências, razão pela qual o seu estudo deve ser feito a partir de seus próprios contornos, com breve referência ao direito comparado.

Jean Jacques Philippe, em seu "La taxe sur la valeur ajoutée" (Ed. Berger Levrault), ao dizer: "Impôt moderne, la TVA est cependant 1 'heritière d'une histoire déjà longue" (p. 21), enumera, embora de forma perfunctória, a evolução desde 1917, passando pelas "Taxes Genérales sur les affaires et taxes uniques spéciales (1917-1936)", "la taxe sur les paiements (1917-1920)", "1'impôt sur chiffre d'affaires (1920-1936)", "les taxes uniques (1925-1936)", "la taxe à la production (1937-1954" até chegar à lei francesa de n 54.404, de 10/4/1954, que instituiu a primeira TVA, substituída posteriormente pela lei de $6 / 1 / 1966$, que passou a vigorar a partir de 1/1/1968.

Por outro lado, Manuel de Juano, em seu "Tributación sobre el valor agregado" (Ed. Victor P. de Zavalia), enumera (p. 22/30) a evolução do IVA, nos diversos países que o adotaram, tratamento fiscal este que serviu de base à solução argentina para hospedar o referido tributo" 2 .

Em verdade, a experiência francesa disseminada pelo mundo, foi sobre o princípio do valor agregado, em que a tributação de cada operação é acrescida à tributação anterior e não, como no princípio da não-cumulatividade, desautorizada a cumulação das imposições anteriores ${ }^{3}$.

Poucos perceberam a distinção, que, todavia, foi apontada por Carlos da Rocha Guimarães, ao dizer:

2 O fato gerador do ICM em Caderno de Pesquisas Tributárias $\mathrm{n}^{2} 3$, ob. cit., p. 287/288.

3 Bernardo Ribeiro de Moraes ainda sobre o sistema francês ensina: "O sistema tributário francês, inspirador do imposto sobre o valor acrescido para a CEE, recebeu, desde logo, uma reformulação, afim de se amoldar às diretrizes da Comunidade Econômica Européia. A TVA de 1954, assim, recebeu novas alteraçōes.

Em 4 de junho de 1965, o Governo de G. Pompidou apresentou, à Assembléia Nacional, um projeto de lei, alterando a legislação relativa ao imposto sobre o valor acrescido, projeto este que se converteu na Lei $n^{2} 6.610$, de 6 de janeiro de 1966, com vigência marcada para o início do exercício financeiro de 1968. Esta lei suprimiu, do sistema tributário, 13 impostos, inclusive a "taxe sur les prestations de services", estendendo o campo de aplicação do tributo sobre o valor acrescido às diversas áreas. Ademais, simplificou-o.

Pela Lei $n^{2}$ 6.610, de 1966, são alcançadas pela TAX SUR LA VALEUR AJOUTÉE, novas atividades, ficando com seu campo de aplicação maior do que o da anterior lei. Estão sujeitas à TVA "as vendas realizadas na França... derivadas de uma atividade de natureza industrial ou comercial, quaisquer que sejam seus fins ou resultados" (art. 39), atingindo também "as operaçōes procedentes do exercício de uma profissão não mercantil, quando sua remuneraçāo constitua um elemento importante do preço de custeio dos produtos ou serviços sujeitos ao imposto" (art. 49, 39) inclusive as atividades oneradas anteriormente pela TPS (extinta), abrangendo, portanto, os arrendamentos, a execução de obras imobiliárias para venda, o fornecimento de trabalho etc. A TVA recai, enfim, sobre "toutes les affaires de production, de distribution et de services".

O princípio regulador das deduçōes foi estabelecido da seguinte forma: o imposto, que tenha onerado o preço de uma operaçāo tributável, deve ser deduzido do imposto aplicável a essa operaçāo, gravando-se portanto, apenas o "valor acrescido" (Caderno de Pesquisas Tributárias n² 3, ob. cit., p. 50/51). 
"Valor acrescido - A Constituição de 1969 não fala em valor acrescido das mercadorias; estabelece que os impostos sobre operações relativas à circulação de mercadorias "não serão cumulativos e dos quais se abaterá, nos termos do disposto em lei complementar, o montante cobrado nas anteriores pelo mesmo ou por outro Estado".

Assim, não se apura a diferença dos valores das mercadorias, para depois calcular o imposto, mas dos impostos de que se credita o adquirente e daqueles de que ele se debita em cada operação. Pode parecer, à primeira vista, que tanto faz tributar a diferença de valor entre as mercadorias alienadas e as adquiridas, ou a diferença entre os impostos devidos por essas operações isoladamente.

No entanto, não é necessariamente assim em todos os casos.

3.2. Alienação com prejuízo - Com efeito, ao examinarmos anteriormente a hipótese das alienações feitas por comerciantes, por preço inferior ao de aquisição, só admitimos a sua tributabilidade "em tese", dado que o princípio da não-cumulatividade, evidentemente, elimina aquela possibilidade, pelo menos em grande parte dos casos.

Dizemos em grande parte dos casos, pois pode haver aqueles em que, pela diferença de alíquotas aplicáveis, a alienação por valor menor do que o da aquisição implique, ainda assim, em tributação.

Um exemplo esclarecerá o que afirmamos: Examinemos o problema à luz do sistema de alíquotas que vigorou durante o ano de 1975, em virtude do disposto na Resolução do Senado de $n^{\circ} 58$, de 1973 . Se naquele ano, o comerciante de um Estado adquirisse mercadoria a comerciante estabelecido em outro Estado pelo valor de 100, teria um crédito de ICM de 12.

Alienando essa mesma mercadoria internamente por 90,0 imposto devido por essa operação seria de 13,05 .

Assim, abatidos os 12 creditados, ainda restaria 1,05 a pagar.

Vemos, assim, que a não-cumulatividade do imposto, e não do valor, como consta do quesito, poderia não eliminar a tributação ainda que a alienação fosse feita em prejuízo, eliminação essa que fatalmente ocorreria se a tributação recaísse sobre a diferença de valores. Essa possibilidade deixou de existir com a promulgação da Resolução do Senado de $\mathbf{n}^{\circ}$ 98, de 1976, que igualou as alíquotas internas e interestaduais.

No entanto, ela continua a existir como uma virtualidade implícita no sistema atual.

Por outro lado, se a Constituição falasse em tributação sobre o valor acrescido, é evidente que aquela operação, ao invés de causar um aumento de tributação, no caso acima figurado, ocasionaria sempre uma diminuição, qualquer que fosse a legislação vigente, relativa às alíquotas.

Vemos, pois, que há, na realidade, diferença entre cálculo do imposto, tomando-se por base o valor acrescido, e apuração de créditos em cada operação, procedendo-se depois à subtração entre o total dos débitos e créditos dessas apurações isoladas" 4 . 
É de se lembrar que no III Simpósio de Direito Tributário, em que se discutiu a matéria e para o qual Carlos da Rocha Guimarães elaborou seu trabalho, muitos autores identificaram as duas hipóteses (não-cumulatividade e valor agregado), a grande maioria também não considerando relevante o principio do valor agregado para determinação da hipótese de imposição do ICMS. As questões 3 e 6 mereceram do Plenário as seguintes conclusões:

"3" Questão: O valor acrescido é circunstância que compõe a hipótese de incidência do ICM?

Comissão I: O "valor acrescido" nada tem a ver com hipótese de incidência do ICM, eis que esta se realiza pela simples ocorrência de uma operação relativa à circulação de mercadorias, devido o ICM sobre o valor dessa operação, com independência de ter sido ela realizada, ou não, com lucro.

O abatimento previsto, constitucionalmente, ê circunstância externa à hipótese de incidência tributária, tendente a dar operatividade ao principio da não-cumulatividade.

Comissão Il (maioria): Não. O valor acrescido não é circunstância componente de incidência porque o ICM incide sobre o preço pleno da mercadoria.

Comissão III: O valor acrescido não é circunstância que compõe a hipótese de incidência do ICM, mesmo porque há casos em que o ICM incide quando não existe valor acrescido e vice-versa. Comissão IV: Não, pois a Constituição Federal fala em "não-cumulatividade" e não em "valor acrescido".

Divergências: $\mathrm{O}$ valor acrescido é circunstância que compõe o FATO GERADOR DO ICM, já que não sendo aspecto material do fato gerador, não pode ser desprezado o elemento quantitativo, sem o qual não existe a obrigação tributária (Bernardo Ribeiro de Moraes e William Gerab).

A Constituição não se refere a valor acrescido. No entanto, o princípio da não-cumulatividade é circunstância que compõe a hipótese de incidência do ICM (Carlos da Rocha Guimarães).

Comissão de redação: "Não. O valor acrescido não é circunstância componente da hipótese de incidência do ICM. O princípio constitucional da não-cumulatividade, consiste, tão-somente, em abater do imposto devido o montante exigível nas operações anteriores, sem qualquer consideração à existência ou não do valor acrescido.

Conclusões do Plenário: 3 a Questão: "Não o valor acrescido não é circunstância componente da hipótese de incidência do ICM.

O princípio constitucional da não-cumulatividade, consiste, tão-somente, em abater do imposto devido o montante exigível nas operações anteriores, sem qualquer consideração à existência ou não de valor acrescido".

$4^{a}$ Questão: É hipótese de incidência do ICM a prevista no artigo $2^{\circ} \S 1^{\propto}$ do Decreto-Lei no ${ }^{406 / 68}$ ?

Comissão I (Posição Majoritária): Adotada nesta Comissão o entendimento de que circulação de mercadoria significa movimentação econômica de um bem, desde a fonte de produção até o consumo, a resposta à 4a questão é afirmativa.

Com efeito, a transferência da mercadoria para estabelecimento do próprio remetente situado em outro Estado induz circulação econômica.

(Posição Minoritária): Não ocorre a hipótese de incidência do ICM no caso do 
art. $2^{2} \S 1^{2}$ do D.L. 406/68. A disciplina, nitidamente preventiva de conflitos de competência tributária, implica o pagamento de ICM em caráter meramente provisório, por ocasião da transferência, enquanto condicionada à ocorrência da última operação tributada no Estado de destino.

Comissão II: Sim.

Comissão III: Sim, porque a transferência de mercadorias entre dois estabelecimentos da mesma empresa implica o curso da mercadoria desde o produtor até o consumidor final.

Comissão IV (Maioria): A saída referida no $\S 1^{\mathfrak{Q}}$, art. $2^{2}$ do Decreto-Lei $406 / 68$ constitui Fato Gerador do ICM.

(Minoria) Não é hipótese de incidência, mas mera base de cálculo.

Comissão de Redação: "A par de estabelecer base de cálculo, o texto do $1^{\circ}$ do art. $2^{2}$ do Decreto-Lei $406 / 68$, contém hipótese específica de incidência do ICM".

$\sigma^{a}$ Questão: À luz das respostas anteriores, qual o aspecto material da hipótese de incidência do ICM?

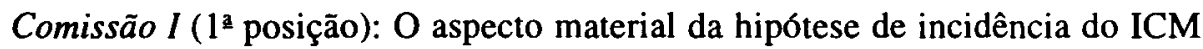
abriga toda operação (atividade ou ação que implique o curso da mercadoria, da fonte de produção até o consumidor relativa à circulação econômica ou jurídica) de bens identificados como mercadorias.

( $2^{\mathrm{a}}$ posição): $\mathrm{O}$ aspecto material da hipótese de incidência do ICM consiste na previsão legal de um negócio jurídico transmissivo da "condição de dono" a outrem de uma mercadoria, segundo um impulso voluntário do transmitente.

Comissão II (maioria): É toda operação (ato que implique o impulsionamento da mercadoria da fonte de produção em direção do consumidor) relativa à circulação (processo de condução da mercadoria desde a fonte de produção até o consumo) de bens identificáveis como mercadorias.

Comissão III: É Fato Gerador do ICM toda operação (ocorrência de fato que implique o curso da mercadoria, da fonte de produção até o consumidor relativa à circulação (econômica ou jurídica) de bens identificáveis como mercadorias, desde que realizadas por comerciantes, industriais ou produtores ou demais categorias de contribuintes previstas em Lei Complementar.

Divergência: A materialidade da hipótese de incidência do ICM não pode ser a realização de um fato (qualquer) que importe num impulso da mercadoria para o consumo. Esta materialidade seria uma materialidade econômica, que jamais poderia se referir a uma figura tipicamente jurídica, como o tributo. É uma resposta que não necessita de dados jurídicos para ser formulada.

Comissão IV: É ato ou conjunto de atos de movimentação ficta, física ou econômica de bens identificáveis como mercadorias (votação unânime, com abstenção do Dr. Carlos da Rocha Guimarães).

Comissão de Redação: "A hipótese de incidência do ICM tem como aspecto material fato que implique na movimentação econômica ou jurídica, de bens identificados como mercadorias, da fonte de produção até o consumo.

Em face do risco de poder interpretar-se que a resposta ao item 1 seria uma resposta pretendendo atingir apenas as Circulações Jurídicas, no sentido que lhes emprestaram suas primeiras discussões sobre a matéria e não ao que efetivamente 
foi deliberado, isto é, de que todas as circulações são jurídicas pois se não fossem, delas a lei não poderia cuidar, podendo ser de 3 naturezas: (a: com a movimentação de mercadorias, sem movimentação de titularidade; b: com movimentação de mercadoria e de titularidade e c: sem movimentação de mercadoria, mas com movimentação de titularidade), decidiu o Plenário, sem prejuízo dessa colocação, para esclarecimento da linha de pensamento predominante em redação não conflitante com a resposta $\mathrm{n}^{\mathrm{1}}$ 1, que: " $\mathrm{A}$ hipótese de incidência do ICM tem como aspecto material fato decorrente de iniciativa do contribuinte, que implique a movimentação econômica ou jurídica, de bens identificados como mercadorias, da fonte de produção até o consumo" 5 .

Parece-me que a diferença entre as duas teorias, que se assemelham, reside na não-partição da carga tributária de operação por operação, mas na manutenção da incidência final com dedução de todas as incidências anteriores. Assim, o exame da matéria não deve ser feito decompondo ou partilhando a incidência múltipla pelas várias operações que compõem o ciclo circulatório, mas considerando uma operação global com compensações das incidências anteriores nas diversas operações.

Escrevi, para explicar tal inteligência, que:

"O princípio da não-cumulatividade é mera técnica de arrecadação. Pretenderam os seus introdutores no sistema nacional, desde 1958 (Lei $n^{\circ} 3.510 / 58$ ), eliminar a "tributação em cascata", terminologia retirada da linguagem econômica, com o que a imposição final incidiria sobre base de cálculo correspondente ao valor operativo com a absorção dos valores intermediários, no que não seria nem superior, nem inferior àquela realidade. Não seria superior, para não provocar a cumulatividade da carga tributária. Não seria inferior para não provocar a sua desoneração, A NÃO SER NOS EXPRESSOS CASOS DE IMUNIDADE OU ISENÇÃO, a partir đa rígida aplicação do princípio constitucional.

O princípio da não-cumulatividade para os dois tributos a que se aplica visa, portanto e exclusivamente, a tributação final do produto (industrial ou em circulação) entregue ao consumo derradeiro, nos termos que a lei complementar determinar, evitando seja, pelo acúmulo da carga tributária incidente nas operações anteriores, superada a alíquota real que recaia sobre a última base de cálculo, a partir de uma alíquota nominal.

É, portanto, o princípio da não-cumulatividade princípio que deve ser examinado a partir da última operação e não a partir de cada operação, pois o que visou o constituinte foi eliminar o efeito cumulativo de operação em operação até a última.

Por esta razão, esclareceu: “e dos quais se abaterá, nos termos do disposto em lei complementar, o montante cobrado nas anteriores pelo mesmo ou por outro Estado".

Embora a expressão "cobrado" possa ser criticada - e sobre ela falaremos mais adiante - a intenção constitucional é inequívoca. O que se pretende não é dividir a carga tributária, como afirmam certos doutrinadores, mas exclusivamente 
impedir que a carga final seja acrescida das cargas tributárias incidentes anteriormente.

O princípio da não-cumulatividade é técnica de arrecadação que deve ser interpretada, nos estritos termos constitucionais, ou seja, da última operação para trás, pois o ciclo operacional que o provoca só se completa naquela fase.

Ao contrário, o pretendido princípio da partição da carga tributária, que a torna autônoma e independente, é técnica que pode inclusive ser defendida para os tributos cumulativos, eis que cada operação vale por si só, devendo ser considerada na inteireza de seus elementos compositores.

Por essa razão, é que não obstante as diferenças entre a técnica do valor agregado e a da não-cumulatividade, há, todavia, zonas de integração evidentes, como a da formulação do principio que não pretende seja a última operação cumulada de cobranças ou incidências anteriores, sendo, dessa forma, o ponto de partida para seu estudo e análise.

Não têm, portanto, razão os criadores da teoria da partição de carga tributária entre as diversas operações, pois não está tal principio implícito na Constituição, eis que contrário ao princípio explícito da não-cumulatividade, apenas aferível a partir da última operação para trás" ${ }^{\prime \prime}$.

É interessante notar que a interpretação que sugeri foi aquela aceita pelo STF, - e não a dos que defendiam a partição da carga tributária -, com o consequiente aproveitamento, nos casos de isenção, dos créditos tributários excluídos, mas com obrigações tributárias nascidas. Em outras palavras, antes da Emenda Passos Porto (E. C. $\mathrm{n}^{\mathrm{Q}} 23 / 83$ ), a isenção gerava direito a crédito e o diferimento não, pois entendeu o S.T.F., que nesta hipótese, a incidência era diferida, não havendo carga tributária anterior a ser aproveitada.

O Ministro Oscar Corrêa, relator do caso no S.T.F., assim justificou sua opção - e a da Corte - pela teoria diferenciada da não-cumulatividade e o consequiente afastamento daquela da partição da carga tributária:

"A prevalecer a tese contrária seria isenção, e não é, como salientou (p. 257): "Mas não é o que acontece com respeito ao simples diferimento, onde a obrigação tributária surge logo, ao realizar-se a operação de circulação de mercadoria, não isenta nem (muito menos) imune. $O$ que não se perfaz de imediato é sua exigibilidade, postergada para o futuro, fato que implica a substituição do sujeito passivo.

Não pode, assim, o diferimento originar o pretenso direito ao crédito do ICM, porque isso equivaleria a identificá-lo como isenção, que não é.

Em suma: pela própria natureza do instituto em análise, o fornecedor da matéria-prima não recolhe o ICM, à saída desta; o adquirente, que pelo mesmo se faz responsável, também não o recolhe à entrada da mercadoria; somente o fará à saída do produto final, não me parece que se lhe deva reconhecer a possibilidade de um crédito por quantia que o Estado não recebeu.

Nessa conclusão, inexiste ofensa ao princípio da não-cumulatividade, pois, não havendo recolhimento anterior não há acúmulo. 
Não há, contudo. renovar deste debate, reiteradamente travado na Corte, hoje pacificado, na orientação indiscrepante que se firmou. E isto convém às relações jurídicas, que requerem estabilidade.

É verdade que alguns Tribunais persistem, em alguns julgados, na linha diversa, tanto mais quanto a própria doutrina ainda se não acomodou.

Mas, vozes já se têm levantado na diretriz adotada pela Corte. É exemplo disso, recente parecer do prof. Ives Gandra da Silva Martins, que acolhendo como "correta jurídica e constitucional" a interpretação desta Corte, analisa-lhe os pressupostos, rebatendo as objeções que contra ela se têm posto, em artigos e pareceres, para colocar nos devidos termos o alcance do princípio da não-cumulatividade estabelecido na Constituição (Ministro Oscar Corrêa, R.E 98.568/SP, D.O. 7/10/83, Ementário 1.311-4)".

Estou convencido de que a não-cumulatividade, que, em verdade, é uma técnica de tributação no país, tem características peculiares, tendo eu escrito sobre ela:

"A não-cumulatividade do ICMS corresponde à teoria do valor agregado com adaptação ao direito pátrio.

Como já se viu, no concernente ao IPI, a eliminação do efeito "cascata" dá-se por força da adoção de uma das três formas de compensação das incidências anteriores, a saber: a do sistema do imposto sobre imposto, a de base sobre base e aquele de apuração periódica.

O Brasil optou pela apuração periódica, pela qual o imposto é compensado, com crédito na entrada, daquele imposto devido no momento da saída da mercadoria, conforme as hipóteses legais, independentemente de ter sido a matéria-prima utilizada ou a mercadoria revendida. Periodicamente, apura-se o imposto devido na entrada das mercadorias e aquele correspondente à saída e determina-se, a partir dessa operação, a obrigação de pagar ou aquela de se manter um crédito para o futuro, por haver mais créditos pelas entradas que pelas mercadorias saídas. Continua o constituinte a incidir na mesma terminologia incorreta do texto anterior. A compensação não se dá por força do imposto cobrado na operação anterior, mas do imposto incidente. $O$ imposto poderá nunca ser cobrado, mas gerará direito a crédito, posto que a incidência é aquela determinadora do crédito, como bem já decidiu o Supremo Tribunal Federal nas questões que lhe foram levadas ou como já demonstrei em parecer sobre a matéria.

O aspecto novo do princípio da não-cumulatividade é o alargamento do espectro impositivo do ICMS, ao abranger os imposto únicos que pertenciam à União e os de serviços de transportes e comunicações.

A não-cumulatividade, à evidência, abrange todas as operações de circulação de mercadorias e de serviços, de tal forma que o crédito correspondente fica assegurado, mesmo que, na prestação de serviços, seja o ICMS compensado contra operação de saída de mercadoria"?

Carlos da Rocha Guimarães viu, também, a diferença e o perfil próprio, no direito brasileiro, da desacumulação de incidências, lembrando-se que, para ele, o ICM era:

7 Comentários à Constituição do Brasil, 60 volume, tomo I, Ed. Saraiva, 1990, p. 396/398. 
"Segundo o nosso ponto de vista, o aspecto material do fato gerador do ICM não pode ser entendido no sentido físico da expressão, isto é, aquele fato gerador não se pode caracterizar pela simples circulação física das mercadorias, ou pela simples circulação econômica, nem por uma determinada base de cálculo.

O contrário é que deve acontecer, isto é, caracterizada a essência do fato gerador, os seus aspectos materiais deverão ser condicionados por aquela conceituação do ser do imposto, ou de sua causa jurídica, como se preferir denominá-lo.

No caso do ICM só a circulação jurídica é que pode dar uma coerência fática a dito fato gerador, explicando por que motivo se tributa a transmissão da propriedade da mercadoria, como no caso do quesito anterior, embora não exista deslocação física, além dos outros casos já examinados.

A nosso ver, portanto, as leis complementares, procurando enumerar casos concretos em que se materializaria o fato gerador do ICM, no intuito de lhe dar uma formulação mais objetiva, ou material, como diz o quesito, afastaram-se não só da letra do C.F., mas também do seu espírito" ${ }^{8}$.

O debate, que perdeu densidade com o advento da E.C. no 23/83, é, todavia, pertinente na medida em que de sua correta exegese depende a própria estabilidade do ICMS, o mais relevante tributo do sistema brasileiro, por ser a fonte de onde todos os Estados obtêm sua principal receita. 
A EVOLUÇÃO DA ORDEM PÜBLICA NO DIREITO INTERNACIONAL PRIVADO

Ref. 0071

Distribuiçāo Brochura 282 págs. Form. 16x23 1979

\section{A EVOLUÇÃO DA ORDEM PÚBLICA NO DIREITO INTERNACIONAL PRIVADO}

Jacob Dolinger

Esta obra versa o princípio da ordem pública no direito internacional privado, que representa a mais importante "válvula de escape" de que se utilizam juízes e tribunais do mundo todo, para deixar de aplicar a lei estrangeira indicada pelas regras de conexāo, sempre que sentirem que a norma estrangeira nāo é consentânea com os princípios fundamentais do direito do foro. 